\title{
КРИПТОВАЛЮТА И ВLОСКСНАІN В МЕЖДУНАРОДНЫХ РАСЧЕТАХ
}

\author{
Хаджиев М.P., \\ Батукаева Л. С-Э., \\ Мусханова Х.Ж., \\ Эскирханова X.C., \\ Юсупова Т.И.
}

ФГБОУ ВО «Чеченский государственный университет»,

г. Грозный, Россия

В статье рассматриваются предпосылки и история появления криптовалют, раскрывается их сущуность и понятие на примере Bitcoin. Исследуется и анализируется Blockchain технология, ее положительнье $и$ оттицательные стороны. Рассматриваются отношение Международного валютного фонда и Всемирного банка к криптовалютам сквозь призму вопроса возможностей использования криптовалют как иного платежного средства в международных расчетах.

Ключевые слова: деньги, криптовалюты, транзакции, Bitcoin, Blockchain, МВФ, ВБ, СДР.

Деньги являются особым продуктом эволюции, выступающим в качестве всеобщего эквивалента, которому присущи функции меры стоимости, средства обращения, платежа, накопления и мировых денег. С развитием всех сфер жизнедеятельности человека, деньги также совершенствуются, переходя из одной формы в другую. Этому способствует поддержка государства, новейшие технологии, экономическая грамотность населения, а также внутренние и внешние экономические отношения, что в совокупности привело к возникновению иной, не имеющей аналога в прошлом, формы денег.

Так по мнению Клауса Шваба, председателя всемирного экономического форума, мы стоим на пороге четвертой промышленной революции, основой которой послужили технологии, ставшие неотъемлемой частью нашей жизни. Взлеты и падения самой известной криптовалюты Bitcoin стали результатом доверия миллионов людей системе Blockchain, доверия к технологии [7].

Криптоволюта является цифровой валютой, не имеющей физического воплощения, каждая из них добывается, хранится и обращается исключительно в сети Интернет с помощью программного обеспечения (ПО) или же мобильных устройств. Приставка crypto означает технологию шифрования, которая обеспечивает защищенность монет от кражи или подделки. В процессе эмиссии и учета криптовалют используется система Proof-of-work (POW) дословно: доказательство работы, которая осуществляет свою деятельность децентрализовано в распределённой компьютерной сети. Механизм POW объединяется двумя составляющими. Во-первых, необходимость выполнения 
задач с определенной сложностью и длительностью времени для осуществления эмиссии, и во-вторых возможностью быстро и легко проверить результат.

Система POW позволяет, в конечном итоге, с помощью узла сети определить фактическое выполнение операции майнером (лицо, участвующее в процессе генерации кода), что также позволяет найти хеш (результат обработки неких данных) заголовок блока.

Эмиссия криптовалют происходит на специализированном программном обеспечении (ПО) в результате майнинга (генерации) уникального кода. Сложность добычи монет увеличивается с увеличением количества майнеров, что обеспечивает ценность криптовалют.

Как любая иная валюта криптовалюта может передаваться между ее пользователями, что именуется «транзакцией». Переводы осуществляются анонимно, но при этом публично представлена цепочка транзакций, где за определенной комбинацией цифр скрывается конкретное лицо. Способность осуществлять транзакции без посредников, за считанные минуты и минимальные затраты, является одной из главной положительной чертой криптовалют.

История возникновения криптовалют берет свое в начале 90-х годов, когда группа участников сетевого движения «суpherpunk» выступила за неприкосновенность личной жизни и невмешательства государства в экономическую деятельность. Участники данного движения были убеждены, что технологии более подходят для защиты данных прав, чем законы. К таким технологиям они относили криптографию, программное обеспечение протоколов взаимодействия, цифровые деньги, идентификацию и верификацию. Главными приоритетам ставились анонимность и минимальные издержки при транзакциях [1].

В 1996 году Ник Сабо, известный американский программист, разрабатывает концепцию «англ. Smart contract — умный контракт», суть которой сводилась к программному обеспечению, при помощи которого было бы возможно выполнять контракты соблюдая их наиважнейшие условия, такие как обязательства, конфиденциальность, раскрытие информации и т.п. Умные контракты основывались на технологии, состоящий из трех частей:

- пользовательские интерфейсы, позволяющие участникам быть в курсе каждой транзакции и лично давать на нее согласие;

- мониторинг, который дает возможность отслеживать, соблюдаются ли условия контракта;

- криптография для создания надежных протоколов, использующихся для мониторинга данных [4, 12].

Данная технология легла в основу первой криптовалюты Биткоин, создателем которой стал человек или же группа людей под псевдонимом Сатоши Накамото, личность которого да сих пор не удалось установить. Сатоши Накамото удалось решить проблему двойной записи, возникающей при 
создании цифровой валюты с помощью пиринговой, децентрализованной денежной системой, основанной на технологии Blockchain.

Технология Blockchain это стабильно увеличивающаяся последовательность блоков, которые распределяются между всеми участниками системы при помощи децентрализации. По мере добавления блока, каждому присоединяется метка, которая именуется хеш-суммой, которая является уникальным кодом, не имеющим аналога. Эти блоки строго в определенном порядке складываются в цепочки откуда и исходит название («Blockchain» - буквально «цепочка блоков»). Блоки устроены таким образом, что при попытке изменить их последовательность, система отклонит цепочку блоков из-за несоответствия структуры и хеш-суммы.

Основным преимуществом системы Blockchain состоит в децентрализации, что обеспечивает доверие людей к ней. Blockchain - это цифровой регистр транзакций, которые хранятся в сети компьютеров (узлов), а не в одном центральном месте и без единого субъекта, контролирующего всю сеть. Так как информация хранится на множество сотнях устройствах она не может быть подвергнута изменению, что обеспечивает надежный обмен данным через электронные сети [5].

Данный факт послужил неопровержимым плюсом в сторону первой криптовалюты, Bitcoin, возникшей и вступившей в обращения после мирового кризиса 2008 года, когда миллионы людей стали жертвами несовершенной централизованной денежной системы и их доверие по отношению к ней значительно снизилось.

Bitcoin - децентрализованная платежная система, использующая одноименную единицу для учета операций. Базовые преимущества технологии, следующие:

1) Анонимность. Счет пользователя не закреплен за определенным лицом, что позволяет осуществлять транзакции анонимно, таким образом, что правоохранительные органы не в силах заморозить счет, запретить осуществление транзакций или же применить санкции получателю.

2) Минимальные комиссии. Комиссия, гарантирующая обрабатывание транзакции, за перемещение Bitcoin от одного получателя к другому составляет 0.0001 btc, что очевидно чрезвычайно мало, в особенности когда сумма транзакции достаточно велика.

3) Скорость перевода. Перевод Bitcoin осуществляется за считанные минуты в любую точку мира лишь при наличии интернета. В то время как банковский перевод между разными странами может продолжаться от нескольких часов до недели.

4) Обозреватель Blockchain. Позволяет проследить откуда и куда производилась транзакция, размер комиссии, все промежуточные адреса транзакции причем вся информация представлена в онлайн режиме и в доступна в ретроспективном периоде, традиционная банковская система не может сегодня предложить такой возможности. 
5) Ограниченность. Как правило пиринговая система запрограммирована на ограниченное количество криптомонет в обращении, в частности количество Bitcoin в системе не будет превышать 21 миллион единиц, и добыча каждой последующей монеты требует больше технологических мощностей и затрат [6].

Войдя в обращение в 2009 году за достаточно короткий срок криптовалюта Bitcoin приобрела высокую ценность. Стоимость криптовалют зависит от спроса и предложения на них. Являясь новшеством Bitcoin привлек к себе внимание многих людей. Столь стремительному росту стоимости данной валюты послужила не только ее практичность и положительные качества, но и возможность заработать в процессе генерации монет и поддерживания пиринговой сети (рис. 1).

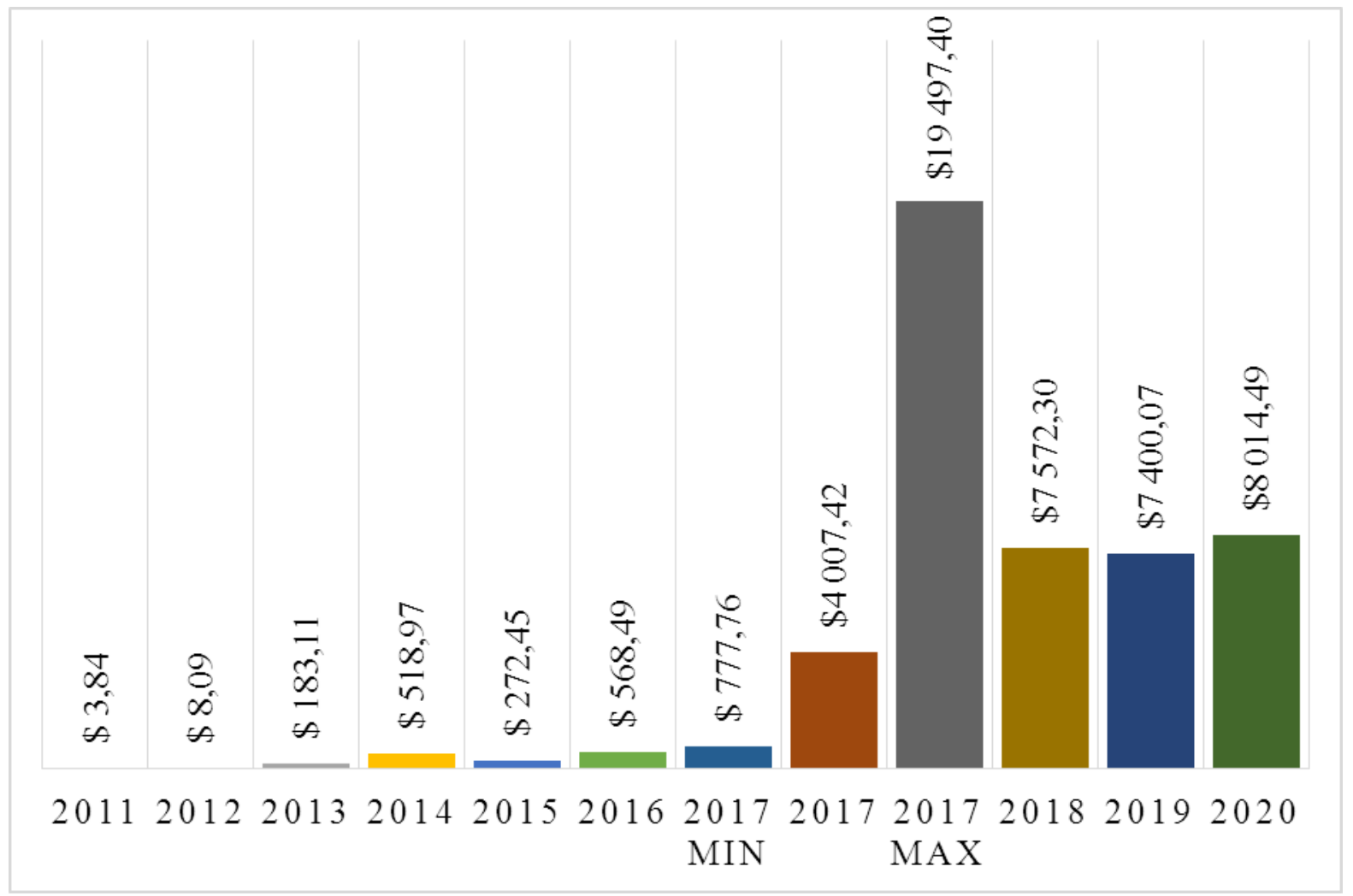

Рис. 1 - Средне-арифметические изменения стоимости ВТС 2011-2020 гг. [8-10]

Bitcoin имеет ряд ограничений, которые побудили программистов со всего мира запустить свои криптовалюты, свободные от данных ограничений. Всю совокупность криптовалют исключив из нее Bitcoin назвали альткоины, количество которых уже сегодня более 5 тыс. с общей капитализацией 198,6 млрд. долл. США. При этом капитализация Bitcoin на сегодняшний день более 126,2 млрд. долл. США, что в общей доле капитализации всех криптовалют составляет более $63,0 \%$.

Однако нас интересуют возможности криптовалют как новой мировой валюты. На протяжении множества лет главной резервной валютой, использующейся для международных расчетов Международным Валютным Фондом (МВФ) и Всемирным банком являлся доллар, однако еще в 1960 году секретарь Казначейства США Генри Х. Фаулер являлся противником единой 
валюты для обеспечения межгосударственных расчетов: «Обеспечение резервов и обменов для всего мира - это слишком много для одной страны и одной валюты» [13].

Для расширения мировой экономике США поддерживал непрерывный дефицит платежного баланса, который вызывал наращивание долларовых резервов в центральных банках Европы. Когда центральные банки выкупали эти доллары за золото, запасы золота в США упали до опасно низкого уровня, что привело к кризису Бреттон-Вудской системы.

Экономист Роберт Триффин предложил создать новые резервные подразделения.Единицы, которые не будут зависеть от золота или валют, но увеличат общую ликвидность в мире. В качестве этих единиц выступили специальные права заимствования [3].

Специальные права заимствования (англ.Special Drawing Rights, SDR) искусственное резервное и платёжное средство, эмитируемое МВФ, имеющие только безналичную форму в виде записей на банковских счетах. Курс СДР определяется на основе долларовой стоимости корзины из пяти ведущих валют: доллар США, евро, китайский юань, йена и фунт стерлингов [2].

Какова же вероятность замены в будущем СДР криптовалютой? В апреле 2019 года МВФ и Всемирный банк выпустили квазикриптовалюту на платформе Blockchain, которую прозвали Learning Coin. Данная криптовалюта не имеет на данный момент денежной ценности и является исключительно обучающей, но не исключена возможность перехода ее в дальнейшем в реальную криптовалюту. МВФ планирует уже сейчас использовать систему Blockchain для борьбы с отмыванием денег и повышения прозрачности банковской деятельности, а также запустить систему интеллектуальных контрактов [11].

Международная резервная валюта должна обладать определенными качествами, чем не обладают криптовалюты на сегодняшний день. К ним относятся в первую очередь стабильность. У криптовалют отсутствует центральный эмитент, гарантирующий стабильность валюты. Для того чтобы признать определенную валюту мировой резервной она должна обладать общепризнанностью в мире, однако криптовалюты являются новым инструментом на финансовом рынке.

Вместе с тем криптовалюта обладает неоспоримыми преимуществами. Криптовалюты высоко ликвидны, имеет высокую скорость и минимальные издержки при транзакциях, позволяют осуществлять переводы без посредников на любую сумму между участниками. Также криптовалюты не требуют расходы на инкассацию, транспортировку и аудит.

МВФ в своем интервью Financial Times заявил, что: «Блокчейнтехнологии и криптоактивы развиваются чрезвычайно быстро, как растет и объем информации, связанной с ними. И центральные банки, и финансовые учреждения должны признать растущий дефицит знаний об этих технологиях среди законодателей, политиков и экономистов» [9]. 
Возможно изучив данную технологию, осознав ее преимущества и скорректировав некоторые недостатки МВФ и Всемирный банк в ближайшем будущем выпустят собственную криптовалюту, которая послужит заменой СДР.

Исследование выполнено при финансовой поддержке РФФИ в рамках научного проекта № 19-310-90035/19.

\section{Список литературы}

1. Дорожкин С. Криптовалюты: теория и практика. Банкаўскі веснік, ЖНIBЕНЬ. 2018 г.

2. Информационный листок: специальные права заимствования (СДР). [Электронный pecypc] - Режим доступа: URL: https://www.imf.org/ru/ About/Factsheets/Sheets/2016/08/01/14/51/Special-Drawing-Right-SDR ～(Дата обращения 17.04.2020).

3. Колдаев О. Парадокс Триффина или почему США сопротивляются цифровым валютам. [Электронный ресурс]. - Режим доступа: URL: https://bitnewstoday.ru/news/paradoks-triffina-ili-pochemu-ssha-soprotivlyayutsyatsifrovym-valyutam/ (Дата обращения 17.04.2020).

4. Сабо Н. Умные контракты (Четвертая революция стоимости). [Электронный pecypc]. - Режим доступа: URL: https://old.computerra.ru/1998/266/194332/ (Дата обращения 17.04.2020)

5. Сатоши Н. Биткойн: электронная денежная система одноранговой сети. [Электронный ресурс] - Режим доступа: URL: https://bitcoin.org/ru/ bitcoinpaper (Дата обращения 17.04.2020)

6. Цакаев А.Х., Хаджиев М.Р., Батукаева Л.С.-Э. Криптовалютная эволюция системы налогообложения. Развитие региональной экономики в условиях цифровизации. Сборник материалов научно-практической конференции, посвященной 80-летию ФГБОУ ВО «Чеченский государственный университет», г. Грозный, 24-25 сентября 2018 г. - Махачкала: Алеф, 2018. С. 296-298.

7. Шваб К. Четвертая промышленная революция. М.: «Эксмо». 2016 г.

8. Coinmarketcap. Информационно-справочный ресурс «Капитализация криптовалютных рынков». [Электронный ресурс] - Режим доступа: URL: http://coinmarketcap.com/ (Дата обращения 17.04.2020)

9. IMF and World Bank explore crypto merits with blockchain project. [Электронный pecypc] - Режим доступа: URL: https://www.ft.com/content/1cfb6d46-5d5a-11e9-939a-341f5ada9d40 (Дата обращения 17.04.2020).

10. Investfunds - сайт об инструментах для частных инвесторов. [Электронный pecypc] - Режим доступа: URL: https://investfunds.ru/indexes/9021/ (Дата обращения 17.04.2020)

11. McIntosh R. IMF \& World Bank Launch "Learning Coin" to Understand Blockchain. [Электронный pecypc] - Режим доступа: URL: 
https://www.financemagnates.com/cryptocurrency/news/imf-world-bank-launchlearning-coin-to-understand-blockchain/ (Дата обращения 17.04.2020).

12. Szabo N. (1997). Formalizing and Securing Relationships on Public Networks. First Monday, 1997. 2(9).

13. The Importance of Global Cooperation. System in Crisis (1959-1971). Part 4: The Dollar Glut. Money Matters: An IMF Exhibit. [Электронный ресурс] Режим доступа: URL: https://www.imf.org/external/np/exr/center/ mm/eng/mm_sc_03.htm/ (Дата обращения 17.04.2020). 